\title{
Melanin Adhesivity for Possible Trapping of SARS-CoV-2 on Chin Straps: A Proof-of-concept Assay Using Model Nanoparticles †
}

\author{
Juan Carlos Stockert ${ }^{1,2 *}$ and Jorge Herkovits ${ }^{3}$ \\ ${ }^{1}$ Universidad de Buenos Aires, Facultad de Medicina, Instituto de Oncología "Angel H. \\ Roffo", Area Investigación, Argentina \\ ${ }^{2}$ Universidad de Buenos Aires, Facultad de Ciencias Veterinarias, Cátedra de His- \\ tología y Embriología, e Instituto de Investigación y Tecnología en Reproducción \\ Animal, Argentina \\ ${ }^{3}$ Instituto de Ciencias Ambientales y Salud, Fundación PROSAMA, Argentina \\ *Corresponding Author: Juan Carlos Stockert, Universidad de Buenos Aires, \\ Facultad de Medicina, Instituto de Oncología "Angel H. Roffo", Area Investigación, \\ Argentina.
}

DOI: $10.31080 /$ ASMI.2020.04.0759
Received: December 21, 2020

Published: January 22, 2021

(C) All rights are reserved by Juan Carlos Stockert and Jorge Herkovits.

\begin{abstract}
In the frame of COVID-19 pandemic, improved chin straps are obviously necessary to better prevent aerial infection by SARS-CoV-2. Adhesivity of melanins could be applied for trapping virus, but due to present limitations to work with infective agents, we have performed a proof-on-concept assay using zinc oxide ( $\mathrm{ZnO}$ ) nanoparticles with similar size (about $100 \mathrm{~nm}$ ) as a virus model. Cotton fabrics were impregnated with allomelanin isolated from black beans, and $\mathrm{ZnO}$ solutions filtered through melanin-containing filters. Results and controls showed that these filters retained efficiently the nanoparticles, suggesting that melanin-treated chin straps could be a valuable and effective protection resource to trap virus and avoid infection. .
\end{abstract}

Keywords: Aerial Infection; Chin Strap; COVID-19; Melanin Adhesivity; Melanin Coating; SARS-CoV-2; Virus Trapping

† Dedicated to Oscar A. Alberti, in memoriam.

\section{Introduction}

In the present scenario of coronavirus disease 2019 (COVID-19) pandemic, SARS-CoV-2 places us in the urgent challenge of reducing morbidity, mortality, and disease infection. In addition to possible treatments [1], it is very important to prevent progression of the disease using protocols based on the reduction of aerial infection by simple chin straps, either alone or impregnated with hypertonic $\mathrm{NaCl}$ solution [2]. The design and use of highly efficient chin straps is strongly recommended, and thus coating and adhesive properties of melanin is coming to this specific purpose.

Melanins (e.g., eu-, pheo-, allomelanin) are polymeric indole or catechol pigments [3], with high light absorption, and wide applications in dermocosmetics, tissue engineering, regenerative medicine [4-6], opto-electronic and photo-acoustic devices [7], antitumoral photothermal therapy [8], and multifunctional platforms in biotechnology [9]. Surface coating and high adhesivity are im- portant properties of melanins $[7,10,11]$. Bearing in mind the rhinopharyngeal access of SARS-CoV-2, it is tempting to speculate that the adhesivity of melanin-impregnated chin straps could retain the virus and then avoid the aerial infection. Due to fashion or esthetic reasons, commercial publicity offers several melanin-named black chin straps, but no scientific evidence supports improved protection for these products.

On the other hand, for the possibility that viral particles could be replaced by model nanoparticles, a simple proof-of-concept was designed using zinc oxide ( $\mathrm{ZnO}$ ) nanoparticles to be trapped on melanin-impregnated fabrics. $\mathrm{ZnO}$ nanoparticles are well known compounds with biomedical applications and useful properties as model nanomaterials $[12,13]$. Since ZnO nanoparticles and SARSCoV-2 virions have very similar size and are delivered in aqueous media, it would be expected that this model system represents a valid assumption for extrapolating results to the case of viral particles. 


\section{Materials and Methods}

ZnO nanoparticles (Sigma-Aldrich 544906, 99\% purity, particle size $<100 \mathrm{~nm}$ ) were used as an inorganic model of the SARS-CoV-2 (virion size between 60 and $140 \mathrm{~nm}$; average size: $100 \mathrm{~nm}$ ). The white $\mathrm{ZnO}$ powder is dissolved in tap water $(0.5 \mathrm{mg} / \mathrm{mL})$, forming a milky colloidal solution.

A dark brown-black solution of melanin (allomelanin, plant catechol-melanin [10]) is obtained from $200 \mathrm{~g}$ of black beans (Phaseolus vulgaris), soaked in $300 \mathrm{~mL}$ of tap water for $24 \mathrm{~h}$ at room temperature (RT), then boiled for $30 \mathrm{~min}$, and cooled to RT. To be used as model filters, small pieces of common cotton fabrics were impregnated with the allomelanin solution at $100{ }^{\circ} \mathrm{C}$ for $5 \mathrm{~min}$, left to cool and air-dried. Commercial chin straps were also soaked with allomelanin. Next, some filters were treated with $4 \%$ formaldehyde in tap water for $30 \mathrm{~min}$ to improve the pigment fixation and to retain the weakly bound fraction.

Ten $\mathrm{mL}$ of the $\mathrm{ZnO}$ solution were placed on dried fabric filters with melanin (a), and without melanin (b), after which the corresponding filtrates were collected. Two types of controls were performed: (1) Once dried, unfixed and formaldehyde-fixed filters were soaked in tap water from 1 to $6 \mathrm{~h}$ to test color fading. (2) Filters without melanin were used to filter $\mathrm{ZnO}$ solutions, to compare the filtrate with that obtained through filters with melanin.

\section{Results and Discussion}

Following melanin impregnation, the rough surface of filters, either fabrics or chin straps, appears stained dark brown-black (Figure 1 A, B). Unfixed filters lose some color by water washing (probably due to pigment excess), whereas those fixed with formaldehyde do not discolor at all (Figure $1 \mathrm{C}$ ).

After filtering $\mathrm{ZnO}$ solutions, melanin filters clearly show the white deposits of retained $\mathrm{ZnO}$ in the center of filters (Figure $2 \mathrm{~A}$ ). $\mathrm{ZnO}$ deposits resist the water washing of filters for several hours, and they remain stuck to the melanin surface. The filtered solutions appear transparent and contrasting with the milky aspect of $\mathrm{ZnO}$ solutions before filtering (Figure $2 \mathrm{~B}, \mathrm{C}$ ).
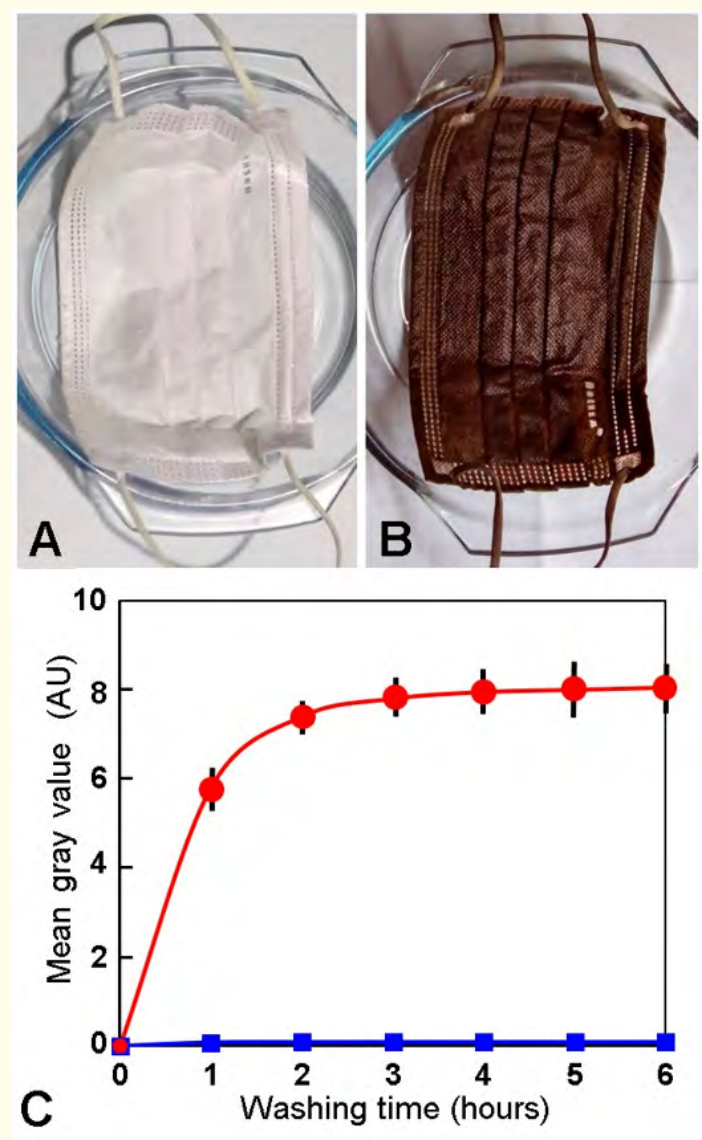

Figure 1: A, B: Commercial chin straps before (A), and after impregnation with allomelanin (B). C: Kinetics of the color removal of allomelanin-impregnated fabrics by water washing. The light brown color of $30 \mathrm{~mL}$ of washing media at increasing times (mean gray values in arbitrary units (AU), and standard deviation when pertinent) were measured by densitometry of photographs using ImageJ $1.52 \mathrm{v}$ software.

On the contrary, ZnO solutions filtered through filters without melanin are identical to the original unfiltered solution, which indicates that melanin is the specific adhesive component that retain the nanoparticles. In this case, no deposits are found on the melanin-free filters. 


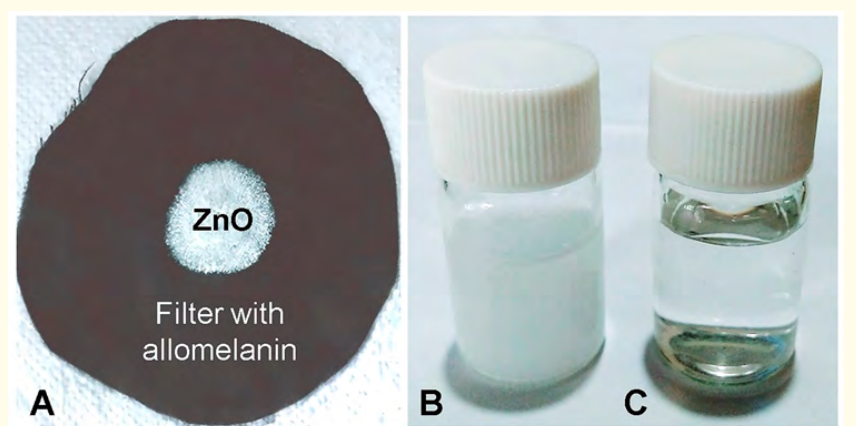

Figure 2: A: Allomelanin-impregnated fabric after filtering of the $\mathrm{ZnO}$ solution. Observe the white deposit of $\mathrm{ZnO}$ retained on the filter. B, C: Comparison between the aspect of $5 \mathrm{~mL}$ of milky $\mathrm{ZnO}$ solution before filtering (B), and clear solution filtered through the allomelanin-treated fabric (C).

As far as we know, no references have been quoted on the proposal of using melanin chin straps to improve virus trapping, and thus this possibility is suggested here. Unfortunately, in the frame of the present-day pandemic and disruptive laboratory work, we could not use infecting virus but only a proof-of-concept approach applying $\mathrm{ZnO}$ nanoparticles. The average size of $\mathrm{ZnO}$ and SARSCoV-2 particles are equivalent, both are surrounded by hydration layers, immersed in aqueous media, and delivered to the filter surface in water. Therefore, it is logical to assume that $\mathrm{ZnO}$ nanoparticles are suitable models of virions.

Adhesivity probably depends on the formation of reactive radicals in quinone, catechol, and phenol components of melanin $[14,15]$, as well as on the negatively charged melanin surface, and easy chelation with di-and trivalent inorganic cations [10]. In addition, polydopamine [16], and synthetic allomelanin [15] would be also useful to replace natural allomelanin. Furthermore, melanin filters could be used to retain other viruses, and also bacteria, aerial xenobiotics and pollutant materials.

\section{Conclusions}

Common cotton fabrics and chin straps impregnated with allomelanin act as filters that retain $\mathrm{ZnO}$ nanoparticles, and therefore they could represent a suitable tool for trapping infective aerial vi- rus as well as other nanomaterials. Relevant advantages of melanin-treated chin straps would be the very low cost, and easy preparation and use even under adverse economic and social conditions.

\section{Acknowledgements}

We acknowledge Fundación PROSAMA Project COVID-19. We are indebted to G.R. Solarz and A. Koss for valuable collaboration.

\section{Conflict of Interest}

The authors declare no conflict of interest.

\section{Bibliography}

1. Sahana S., et al. "A venture to discover the treatment of coronavirus disease 2019 (COVID 19): SARS-CoV-2". Acta Scientific Microbiology 3.10 (2020): 53-58.

2. Quan FS., et al. "Universal and reusable virus deactivation system for respiratory protection". Scientific Reports 7 (2017): 39956.

3. Panzella L., et al. "The late stages of melanogenesis: exploring the chemical facets and the application opportunities". International Journal of Molecular Sciences 19 (2018): 1753.

4. Solano F. "Melanin and melanin-related polymers as materials with biomedical and biotechnological applications-Cuttlefish ink and mussel foot proteins as inspired biomolecules". International Journal of Molecular Sciences 18.7 (2017):1561.

5. Park J., et al. "Recent advances in melanin-like nanomaterials in biomedical applications: a mini review". Biomaterials Research 23 (2019): 24.

6. Mavridi-Printezi A., et al. "Bio-applications of multifunctional melanin nanoparticles: From nanomedicine to nanocosmetics". Nanomaterials 10 (2020): 2276.

7. Cavallini C., et al. "Melanin and melanin-like hybrid materials in regenerative medicine". Nanomaterials 10 (2020): 1518.

8. Colombo LL., et al. "Photothermal effect by 808-nm laser irradiation of melanin: A proof-of-concept study of photothermal therapy using B16-F10 melanotic melanoma growing in BALB/c mice". Biomedical Optics Express 10.6 (2019): 29322941. 
9. Liu H., et al. "Melanin-like nanomaterials for advanced biomedical applications: a versatile platform with extraordinary promise". Advanced Science 7 (2020): 1903129.

10. d'Ischia M., et al. "Melanins and melanogenesis: from pigment cells to human health and technological applications". Pigment Cell Melanoma Research 28 (2015): 520-544.

11. Scognamiglio F., et al. "Adhesive coatings based on melaninlike nanoparticles for surgical membranes". Colloids and Surfaces. B: Biointerfaces 155 (2017): 553-559.

12. Król A., et al. "Zinc oxide nanoparticles: Synthesis, antiseptic activity and toxicity mechanism". Advances in Colloid Interface Science 249 (2017): 37-52.

13. Mishra PK., et al. "Zinc oxide nanoparticles: a promising nanomaterial for biomedical applications". Drug Discovery Today 22.12 (2017): 1825-1834.

14. Land EJ., et al. "Quinone chemistry and melanogenesis". Methods in Enzymology (2004): 88-109.

15. Zhou X., et al. "Artificial allomelanin nanoparticles". ACS Nano 13.10 (2019): 10980-10990.

16. Liu Y., et al. "Polydopamine and its derivative materials: synthesis and promising applications in energy, environmental, and biomedical fields". Chemical Review 114 (2014): 50575115.

\section{Assets from publication with us}

- Prompt Acknowledgement after receiving the article

- Thorough Double blinded peer review

- Rapid Publication

- Issue of Publication Certificate

- High visibility of your Published work

Website: www.actascientific.com/ Submit Article: www.actascientific.com/submission.php Email us: editor@actascientific.com

Contact us: +919182824667 